\title{
Building a Foundation to Reduce Health Inequities: Routine Collection of Sociodemographic Data in Primary Care
}

\author{
Andrew D. Pinto, MD, CCFP, MSc, Gabriela Glattstein-Young, MD, MPH, \\ Anthony Mohamed, MES, Gary Bloch, MD, CCFP, Fok-Han Leung, MD, CCFP, and \\ Richard H. Glazier, MD, CCFP, MPH
}

Introduction: Detailed data on social determinants of health can facilitate the identification of inequities in access to health care. We report on a sociodemographic data collection tool used in a family medicine clinic.

Methods: Four major health organizations in Toronto collaborated to identify a set of 14 questions that covered a range of social determinants of health. These were translated into 13 languages. This survey was self-administered using an electronic tablet to a convenience sample of 407 patients in the waiting room of a primary care clinic. Data were uploaded directly to the electronic medical record.

Results: The rate of valid responses provided for each question was high, ranging from $84 \%$ to $100 \%$. The questions with the highest number of patients selecting "do not know" and "prefer not to answer" pertained to disabilities and income. Patients reported finding the process acceptable. In subsequent implementation across 5 clinics, 10,536 patients have been surveyed; only 724 (6.9\%) declined to participate.

Conclusion: Collecting data on social determinants of health through a self-administered survey, and linking them to a patient's chart, is feasible and acceptable. A modified survey is now administered to all patients. Such data are already being used to identify health inequities, develop novel interventions, and evaluate their impact on health outcomes. (J Am Board Fam Med 2016;29:348-355.)

Keywords: Epidemiology, Health Care Disparities, Social Determinants of Health, Social Problems

Our health is influenced by the complex interaction of individual- and community-level social and economic factors. These are called "social determinants of health" (SDOHs) and include income,

This article was externally peer reviewed.

Submitted 31 August 2015; revised 22 February 2016; accepted 25 February 2016

From the Department of Family and Community Medicine, St. Michael's Hospital, Toronto, Ontario, Canada (ADP, GB, F-HL, RHG); the Department of Family and Community Medicine, Faculty of Medicine, University of Toronto, Toronto, Ontario, Canada (ADP, GB, F-HL, RHG); the Centre for Research on Inner City Health, Li Ka Shing Knowledge Institute, St. Michael's Hospital, Toronto, Canada (ADP, RHG); the Division of Clinical Public Health, Dalla Lana School of Public Health, University of Toronto, Toronto, Ontario, Canada (ADP, RHG); the Department of Family Practice, Faculty of Medicine, University of British Columbia, Vancouver, British Columbia, Canada (GG-Y); Inner City Health, St. Michael's Hospital, Toronto, Ontario, Canada (AM); and the Institute for Clinical Evaluative Sciences, Toronto, Ontario, Canada (RHG).

Funding: ADP is financially supported by the Department of Family and Community Medicine, St. Michael's Hospital; the Department of Family and Community Medicine, Faculty of Medicine, and the Dalla Lana School of Public Health, social status, education, the social and physical environments, gender, and culture. ${ }^{1}$ Understanding the SDOHs-and addressing these factors to reduce health inequities - has steadily risen up the

University of Toronto; and the Centre for Research on Inner City Health, Li Ka Shing Knowledge Institute, St. Michael's Hospital. ADP was a Canadian Institutes of Health Research Strategic Training Fellow in the Action for Health Equity Interventions (ACHIEVE) program and in the Canadian Institutes of Health Research Transdisciplinary Understanding and Training on Research- Primary Health Care (TUTOR$\mathrm{PHC}$ ) program during this research project. RHG is financially supported by the Department of Family and Community Medicine, St. Michael's Hospital and the Department of Family and Community Medicine, Faculty of Medicine, University of Toronto. The authors gratefully acknowledge the support of the Canadian Institutes of Health Research and the Peterborough KM Hunter Charitable Foundation.

Conflict of interest: none.

Disclaimer: The views expressed in this publication are the views of the authors and do not necessarily reflect the views of the Ontario Ministry of Health and Long-Term Care.

Corresponding author: Andrew D. Pinto, MD, CCFP, Department of Family and Community Medicine, St. Michael's Hospital, 410 Sherbourne Street, 4th Floor, Toronto, Ontario, Canada M4X 1K2 (E-mail: andrew.pinto@utoronto.ca). 
agenda of health professionals, ${ }^{2,3}$ health organizations $^{4-6}$ and policymakers. ${ }^{7,8}$

How SDOHs are linked to better or worse health outcomes is becoming better understood. One link in the causal chain is access to health services. ${ }^{8,9}$ Even in countries with publicly financed health insurance to cover the cost of physician visits and hospitalizations, not all individuals enjoy the same access to such health services. In Canada, for example, those with a low income have been found to have less access to specialists than the wealthy. ${ }^{10-13}$ Those with lower educational attainment have less access to specialists than those with higher educational attainment. ${ }^{14}$ Gay, lesbian, and bisexual Canadians report more negative experiences within the health system and greater unmet health needs. ${ }^{15,16}$ Transgender patients report high rates of discrimination when seeking health care. ${ }^{17}$ New immigrants to Canada access fewer primary care services than their Canadian-born counterparts. ${ }^{18-20}$ Other factors that influence who receives service and who does not, and the quality of the service received, include housing status, ${ }^{21}$ whether a patient has a disability, ${ }^{22}$ the language a patient speaks, ${ }^{23}$ and their race or ethnicity. ${ }^{24}$

Such evidence of disparities in access to health services and inequitable health outcomes is typically derived from the combination of administrative data and surveys. When patient demographic data exist, they are often not self-reported. Few health service organizations routinely collect data on a sociodemographic variables, and fewer still link such data to individual patient files. ${ }^{25}$

Studies to date ${ }^{26,27}$ have identified several barriers to collecting sociodemographic data, including a lack of consensus about which questions to ask, how to word these questions, how best to survey patients, and concerns that asking such questions could disrupt the therapeutic relationship. ${ }^{28-31}$ Some patients may question the utility of sociodemographic data collection and worry about discrimination. $^{25,32}$ Moreover, public awareness of health inequities remains low $^{33}$-hence the need for clarity around the purpose behind any such data collection. ${ }^{27,34}$

This article reports lessons learned from the collection of sociodemographic data within a Canadian family medicine clinic. We examined whether it was feasible and acceptable to ask patients about sociodemographic variables through a tablet-based survey administered in the waiting room. We begin by outlining the development of the survey. We then present the findings from testing this survey at an outpatient primary care facility and discuss its subsequent implementation into the routine workflow across multiple clinic sites.

\section{Methods \\ Setting}

The Department of Family and Community Medicine at St. Michael's Hospital is a large, academic family practice unit in downtown Toronto, a city of approximately 2.6 million people. Over 200 health professionals, including over 60 full- and part-time physicians, serve 35,000 patients at 5 separate clinics. A broad cross section of the community is seen at St. Michael's Hospital, which has a particular mandate to provide care to marginalized populations. ${ }^{35}$ This study received the approval of the St. Michael's Hospital Research Ethics Board.

In the fall of 2010 a number of physicians and staff of the Department of Family and Community Medicine expressed an interest in the routine collection of sociodemographic data. This led to involvement in a joint initiative with 3 other health organizations in Toronto: the Centre for Addiction and Mental Health, Mount Sinai Hospital, and Toronto Public Health. Two authors (ADP, AM) were members of the steering committee of that project. Representatives from these institutions had been meeting regularly since 2009 and had identified a need to collect sociodemographic data from their patient populations. Question domains were identified based on studies that identified variables that are consistently tied to differences in access to health services, the quality of health services, and health outcomes. Interviews were conducted with key informants from 11 local organizations that were already collecting sociodemographic information. The wording of questions was informed by a literature review and refined through an iterative process, with numerous meetings and consultations involving staff and physicians at all 4 organizations over 4 years (Online Appendix 1). To ensure accessibility, the survey was translated into Arabic, French, Spanish, Russian, Simplified Chinese, Tamil, Farsi, Korean, Portuguese, Punjabi, Traditional Chinese, and Vietnamese. These were the most commonly requested languages when interpreter services were sought at the 4 participating institutions. Translated 
versions were back-translated into English to ensure the quality of the translations.

Best practices in data collection methods were identified and incorporated into data collection. Self-reporting by patients was identified as being essential for all questions, particularly race or ethnicity. ${ }^{36-38}$ Data collection was integrated into the standard workflow at registration, given that this is an entry point for all patients, who are available while waiting to be seen. Given that success is related to staff buy-in, ongoing engagement and meaningful involvement of staff was prioritized throughout the pilot study and implementation process. ${ }^{27}$ Finally, we understood that it was important to integrate data into existing electronic data systems to eliminate the need to reenter data and to allow the collected data to be linked to a patient's electronic medical record (EMR). ${ }^{39}$

\section{Population and Sampling}

The survey (Online Appendix 2) was piloted with approximately 400 adult ( $\geq 16$ years old) patients at each of the 4 participating sites during the summer of 2012. Each site used a different method to survey patients; St. Michael's Hospital was the only site to use an electronic tablet interface. Further details on the other collaborating sites are available elsewhere. ${ }^{40}$ One clinic site at St. Michael's Hospital, the Health Centre at 80 Bond, was chosen for the pilot because it had wireless Internet and the staff had experience in supporting similar research activities. Posters advertising the project were displayed in the waiting room for all patients to see, and information pamphlets were available. A convenience sample of patients attending the clinic was created. Data collectors were 2 multilingual postgraduate students who received training before any data collection efforts. A scripted dialog was used to invite patients waiting for an appointment to participate in the study, and each was provided an information sheet in English. This was not translated into other languages. The number of patients who declined the survey was not tracked during this pilot phase. If a patient agreed to participate, his or her medical record number was used to link the survey responses to the patient's EMR. The patient was then provided with an iPad connected to the Internet using a secure, password-protected wireless network. No paper version of the survey was available in the case of failure of the tablet. The opening screen prompted participants to select a language; a subsequent screen took participants through the consent process, which was in the language that the participant had selected. Following this, the 14 survey questions were presented; the options "Prefer not to answer" and "Do not know" were available for each question. Each survey ended with questions to the participant about their experience responding to the survey. Data collectors were directed to encourage patients to complete the survey on their own, with assistance only provided upon request. Participants entered responses directly on the tablet, and their responses were visible only to themselves. Exclusion criteria included inability to provide informed consent and not registration as a patient of the family practice unit. Data were posted within 48 hours to the physician's EMR result inbox labeled "socio-demographic data." After the results were viewed and the physician acknowledged receipt, this information was posted into the patient's record as entered.

\section{Data Analysis}

All data were extracted from the EMR at the end of the study. Descriptive statistics were used to assess the overall response rate for each question. Data on the language chosen by participants to complete the survey was not collected because of how the tablets were programmed. For the purposes of this study, we defined a valid response as any of the available options, including "Do not know" and "Prefer not to answer." An invalid response was defined as either no data (patient skipped the question without choosing any available option) or an inappropriate response, such as stating their year of birth was before 1900. The tablets were not programmed to reject impossible answers for questions that required direct entry. Each participant could provide a comment at the end of the survey if they wished. Data collectors submitted a summary of their experience and were also interviewed; notes were taken during this conversation. Comments provided by patients and data collectors were independently analyzed by 2 members of the study team (ADP, GG-Y) using thematic analysis. Once key themes were agreed on, they were confirmed with the entire study team and representative quotes were identified. 
Table 1. Responses to the Pilot of Sociodemographic Questions Answered by 407 Participants at the Department of Family and Community Medicine, St. Michael's Hospital (July-August, 2012)

\begin{tabular}{|c|c|c|c|c|c|}
\hline Questions* & $\begin{array}{l}\text { Appropriately } \\
\text { Answered }^{+}\end{array}$ & $\begin{array}{l}\text { Prefer Not } \\
\text { to Answer }\end{array}$ & $\begin{array}{l}\text { Do not } \\
\text { Know }^{\dagger}\end{array}$ & $\begin{array}{l}\text { Blank/Inappropriate } \\
\text { Response }\end{array}$ & $\begin{array}{c}\text { Valid } \\
\text { Responses (\%) }\end{array}$ \\
\hline $\begin{array}{l}\text { 1. What language would you feel most } \\
\text { comfortable speaking in with your health care } \\
\text { provider? }\end{array}$ & 405 & 0 & 2 & 0 & 100 \\
\hline $\begin{array}{l}\text { 2. How would you rate your ability to speak and } \\
\text { understand English? }\end{array}$ & 406 & 1 & 0 & 0 & 100 \\
\hline $\begin{array}{l}\text { 3. In what language would you prefer to read } \\
\text { health care information? }\end{array}$ & 381 & 2 & 1 & 23 & 94.3 \\
\hline 4a. Were you born in Canada? & 403 & 4 & 0 & 0 & 100 \\
\hline *4b. If no, what year did you arrive in Canada? & 108 & 0 & 0 & 39 & 73.5 \\
\hline 5. In what year were you born? & 357 & 17 & 0 & 33 & 91.9 \\
\hline $\begin{array}{l}\text { 6. Which of the following best describes your } \\
\text { race? }\end{array}$ & 400 & 6 & 1 & 0 & 100 \\
\hline 7. What is your religious or spiritual affiliation? & 391 & 10 & 6 & 0 & 100 \\
\hline 8. Do you have any of the following disabilities? & 315 & 20 & 8 & 64 & 84.3 \\
\hline 9. What is your gender? & 405 & 1 & 1 & 0 & 100 \\
\hline 10. What is your sexual orientation? & 391 & 14 & 2 & 0 & 100 \\
\hline $\begin{array}{l}\text { 11. What was your total family income before } \\
\text { taxes last year? }\end{array}$ & 351 & 41 & 15 & 0 & 100 \\
\hline $\begin{array}{l}\text { 12. How many people does this income } \\
\text { support? }\end{array}$ & 343 & 25 & 8 & 30 & 92.4 \\
\hline 13. What type of housing do you live in? & 400 & 7 & 0 & 0 & 100 \\
\hline 14. In general, would you say your health is... & 404 & 3 & 0 & 0 & 100 \\
\hline
\end{tabular}

Data are counts unless otherwise indicated.

*Follow-up item.

${ }^{\dagger}$ Included in valid responses.

\section{Results}

The survey was tested with 407 patients within the family practice unit at St. Michael's Hospital. The rate of valid responses (any option chosen, including "Do not know" and "Prefer not to answer") provided for each question was high, ranging from $84 \%$ to $100 \%$ (Table 1$)$. The lowest rate $(73.5 \%)$ was for the follow-up to item 4a: "In what year did you arrive in Canada?" Blank or inappropriate responses occurred at the highest frequencies for questions about birth year (8.1\%), number of dependents $(7.4 \%)$, and preferred language in which to read health care information $(5.7 \%)$. The frequency of "Do not know" and "Prefer not to answer" responses was $>3 \%$ for the majority of questions. Questions with the highest frequency of "Prefer not to answer" responses were related to financial status, including income $(10.1 \%)$ and the number of people supported by the income (6.1\%). Less than $5 \%$ preferred not to answer questions about birth year (4.2\%), sexual orientation (3.4\%), religion (2.5\%), and housing (1.7\%), whereas $<2 \%$ preferred not to answer questions regarding race
(1.5\%), gender $(0.2 \%)$, and language abilities $(\leq 0.7 \%)$. Stated another way, over $95 \%$ of participants were willing to answer such questions. The highest frequency of "Do not know" responses were attributed to questions on income (3.7\%), the number of people supported by the income $(2.0 \%)$, and religious affiliation (1.5\%).

\section{Feedback from Participants}

Of 407 respondents, $50(12.3 \%)$ provided a comment at the end of the survey. Of these, 18 respondents stated simply that they had no comment, 17 had a positive comment (eg, "It was fine," "Good survey," "Simple to understand"), and 8 made a suggestion for improvement (eg, "I do identify as queer and trans, but have not and do not plan to transition to male. So it would have been helpful to have a blank space under gender to explain that!"). Only 7 respondents provided comments that were negative, including 5 who reported feelings of discomfort in responding to the survey (eg, "Some questions are a bit too personal," "Income question made me 
uncomfortable. I would like to know that everyone would get the same standard of care no matter the income.") or a lack of clarity on the survey's purpose (eg, "Question clear. The purpose of the survey not so much!").

Regarding the survey question that asked about race, 2 respondents felt that there should have been a response that allowed for the selection of "Canadian." Two respondents pointed out the complexity of using terms like race when asking someone to self-identify with a racial/ethnic category: "I found some of your categories to be problematic. . . . Race, for instance, is a term that is a cultural construct, and therefore relatively meaningless in relation to biological health. It is also difficult to correlate it with geography. . . . Fundamentally, ethnicity would have been a more valuable category."

\section{Feedback from Data Collectors}

As noted, in this pilot study the patients who refused to participate in the survey were not counted. Data collectors anecdotally reported that non-English-speaking patients were more likely to refuse to participate, despite the availability of translated surveys. Older patients seemed to have the greatest difficulty when it came to viewing, zooming in, and selecting options on the tablet interface. Some patients reported that they had too many tasks to complete at the clinic already and reported this as a reason for survey refusal. Data collectors also reported that a reason patients did not complete the survey was they were called into an appointment midway through completion. Data collectors also reported that willingness to complete the survey depended on whether others in the waiting room had accepted or declined.

\section{Discussion}

In this study we found that asking questions about the sociodemographic characteristics of individual patients using a tablet was feasible and acceptable. Participants were willing to answer questions about sensitive subjects, including sexual orientation, gender, housing, religion, and race or ethnicity. As expected, the highest rate of "Do not know" and "Prefer not to answer" responses were for questions about income. By directly linking detailed sociodemographic data to the EMR, we are able to identify health inequities in real time, develop tailored interventions, and much more easily evaluate the impact of such interventions on health outcomes.

This study has a number of strengths, including that it examines the pragmatic use of a survey in the waiting room of a busy primary care setting, and questions include sensitive topics such as sexual orientation, income, and race/ethnicity. This is, to our knowledge, the first study of its kind in Canada, where the routine collection of sociodemographic data in health settings is rare. This study also has a number of limitations. One key limitation was that the precise number of patients who declined to participate was not tracked as part of the pilot phase. ${ }^{40}$ The data collectors were not instructed to collect this information. While this is certainly an oversight for a pilot study of a survey, the decline rate with our small sample is not anticipated to be representative of the decline rate in actual practice. In the implementation of these questions across our department, of 10,536 patients surveyed between December 2013 and August 2015, only 724 declined $(6.9 \%)$. Future research is planned to examine nonresponse bias and to interview patients about why they may not complete such a survey. Another limitation is that the language chosen by a participant was not tracked. This was not possible, based on how the tablets were programmed for this pilot. In addition, the information sheet provided to patients was only in English; hence some non-English-speaking patients may have declined to participate because they could not understand the rationale for the study. However, the consent process that patients completed on the tablet was available in all languages. Also, further information on how patients perceive such a survey could have been gathered through interviews or focus groups. Such work has already been conducted in Canada, however, including a survey of $>1000$ adults that found that most supported their family physician collecting such data (Miller L, personal communication, 2015).

Our experience is comparable to other studies of the collection of sociodemographic data. Studies from the United States have described that using a computer interface as part of the registration process is efficient and feasible. ${ }^{32,41}$ Participants in other studies have also reported 
broad support for collecting sociodemographic data, with some reservations if it is unclear why the data are being collected. ${ }^{28,29,42}$ Similar to our study, others have found that race and ethnicity questions can be controversial, something that can be ameliorated by allowing patients to selfidentify in their own terms. ${ }^{27,36,43}$

Following this pilot, in December 2012 the Toronto Central Local Health Integration Network, the regional health authority, directed all hospitals in their catchment area to collect sociodemographic data. Other jurisdictions have mandated such data collection. ${ }^{44}$ Eight questions were recommended. ${ }^{45}$ Within the family medicine department at St. Michael's Hospital, the routine collection of sociodemographic data occurs at all 6 clinic locations. A third-party organization has been contracted to provide equipment and technical support. This includes programming the tablet interface, uploading responses to the patients' EMRs via a secure server, developing a flag at patient registration to alert staff of prior survey completion to reduce the number of times a patient may be asked to complete the questionnaire, and training staff to use the system. A clerical staff person at each site oversees day-to-day processes. They reported that patients are willing to complete the survey when they understand it is about improving the quality of their care and the care of others. For patients who are not comfortable with using a tablet, a paper version of the survey is available. Clerical staff then use the tablet interface at a later point to enter the patients' written answers.

A number of small changes were made to the questions based on the results of the pilot study and should be noted (Online Appendix 3). Eight additional languages were added to provide more options to patients. Based on reports of confusion about the term race, the question now asks about "racial or ethnic group." "Aboriginal" as a racial or ethnic category was expanded to 4 separate categories ("First Nations," "Inuit," "Métis," and "Indigenous not included elsewhere"). The question on gender was changed to "sex/ gender" so that intersex could be included without adding to the total number of questions yet could continue to recognize the difference between these 2 terms. For the question on sexual orientation, "male-female relationships" was added in brackets after "heterosexual" because some patients were unfamiliar with the term. "Trans-Male to Female" and "Trans-Female to Male" were added as options under the question on sex/gender based on feedback to allow differentiation of experiences and outcomes between these groups. The financial ranges under the income question were expanded to make it easier for patients to feel comfortable answering (eg, making the lowest category $<\$ 30,000)$. Further, the data are now entered directly into the electronic chart immediately after the survey is complete (ie, they do not enter physician's EMR inbox).

Plans for this data include using it to identify and reduce inequities in access to primary health care services (eg, identify racial or ethnic groups that have particularly low cancer screening rates and implement targeted screening efforts); to identify and reduce inequities in health outcomes (eg, identify the language preference of people with poorly controlled diabetes and ensure translation services are available and used); and to target health promotion interventions (eg, provide information on pre- and postexposure prophylaxis to men who have sex with other men who are human immunodeficiency virus negative).

A number of questions remain about collecting sociodemographic data within primary care settings. How should further changes to the wording of questions or the available answer options be implemented, and how will this affect the analysis of data already collected? How can data quality be assessed and what are benchmarks? How can missing data be addressed in a simple and practical way? How often should patients be asked these questions, and how can tools within the EMR be used to prompt a repeat survey? How can patients and communities be involved in the interpretation of data and trends? Each organization will need to develop an infrastructure to manage these concerns.

Collecting data on SDOHs is feasible in a primary health care setting. These data allow health organizations to see who is being served and who is not and to identify differences in outcomes across groups. In turn, these data can inspire new programs to reduce inequities, and if tracked over time, they can be used to evaluate the impact of such interventions. By implementing this survey, health system leaders have a new and powerful tool 
to use to improve individual and population health and achieve the "Triple Aim."7

This study occurred as part of the Tri-Hospital + TPH Health Equity Data Collection Research Project, a larger collaboration among a number of Toronto institutions, with support from the Toronto Central Local Health Integration Network. The authors particularly appreciate the advice of Marylin Kanee, Branka Agic, and Caroline Wai on the content of this article. The authors also thank Darshanand Maraj for his assistance with editing this manuscript.

\section{References}

1. Public Health Agency of Canada. What determines health? Modified October 21, 2011. Available from: http://www.phac-aspc.gc.ca/ph-sp/determinants/ index-eng.php. Updated 2001. Accessed March 31, 2016.

2. Social determinants of health - what doctors can do. London: British Medical Association; 2011. Available from: www.bma.org.uk/ /media/files/pdfs/ working for change/improving health/socialdeterminantshealth.pdf. Accessed March 31, 2016.

3. Physicians and health equity: opportunities in practice. Ottawa: Canadian Medical Association; 2013. Available from: http://nccdh.ca/resources/entry/ physicians-and-health-equity. Accessed March 31, 2016.

4. Garg A, Jack B, Zuckerman B. Addressing the social determinants of health within the patient-centered medical home: lessons from pediatrics. JAMA 2013; 309:2001-2.

5. Manzano AT, Raphael D. CPHA and the social determinants of health: an analysis of policy documents and statements and recommendations for future action. Can J Public Health 2010;101:399-404.

6. Pinto AD, Manson H, Pauly B, Thanos J, Parks A, Cox A. Equity in public health standards: a qualitative document analysis of policies from two Canadian provinces. Int J Equity Health 2012;11:28.

7. Berwick DM, Nolan TW, Whittington J. The triple aim: care, health, and cost. Health Aff (Millwood) 2008;27:759-69.

8. Marmot M, Friel S, Bell R, Houweling TA, Taylor $\mathrm{S}$; Commission on Social Determinants of Health. Closing the gap in a generation: health equity through action on the social determinants of health. Lancet. 2008;372:1661-9.

9. Kosteniuk JG, Dickinson HD. Tracing the social gradient in the health of Canadians: primary and secondary determinants. Soc Sci Med 2003;57:263-76.

10. van Doorslaer E, Masseria C, Koolman X; OECD Health Equity Research Group. Inequalities in access to medical care by income in developed countries. Can Med Assoc J 2006;174:177-83.

11. Alter D, Naylor C, Austin P, Chan B, Tu J. Geography and service supply do not explain socioeco- nomic gradients in angiography use after acute myocardial infarction. Can Med Assoc J 2003;168:261-4.

12. Dunlop S, Coyte PC, McIsaac W. Socio-economic status and the utilisation of physicians' services: results from the Canadian National Population Health Survey. Soc Sci Med 2000;51:123-33.

13. Roos NP, Mustard CA. Variation in health and health care use by socioeconomic status in Winnipeg, Canada: does the system work well? Yes and no. Milbank Q 1997;75:89-111.

14. Glazier RH, Agha MM, Moineddin R, Sibley LM. Universal health insurance and equity in primary care and specialist office visits: a population-based study. Ann Fam Med 2009;7:396-405.

15. Bergeron S, Senn CY. Health care utilization in a sample of Canadian lesbian women: predictors of risk and resilience. Women Health 2003;37:19-35.

16. Tjepkema M. Health care use among gay, lesbian and bisexual Canadians. Health Rep 2008;19:5364.

17. Bauer GR, Scheim AI, Deutsch MB, Massarella C. Reported emergency department avoidance, use, and experiences of transgender persons in Ontario, Canada: results from a respondent-driven sampling survey. Ann Emerg Med 2014;63:713-20.e1.

18. Wang $\mathrm{L}, \mathrm{Hu} W$. Immigrant health, place effect and regional disparities in Canada. Soc Sci Med 2013;98: $8-17$.

19. Beiser M, Goodwill AM, Albanese P, McShane K, Nowakowski M. Predictors of immigrant children's mental health in Canada: selection, settlement contingencies, culture, or all of the above? Soc Psychiatry Psychiatr Epidemiol 2014;49:743-56.

20. Pottie K, Batista R, Mayhew M, Mota L, Grant K. Improving delivery of primary care for vulnerable migrants: Delphi consensus to prioritize innovative practice strategies. Can Fam Physician 2014;60:e32-40.

21. Wen CK, Hudak PL, Hwang SW. Homeless people's perceptions of welcomeness and unwelcomeness in healthcare encounters. J Gen Intern Med 2007;22:1011-7.

22. Sullivan WF, Berg JM, Bradley E, et al. Primary care of adults with developmental disabilities: Canadian consensus guidelines. Can Fam Physician 2011;57: 541-53, e154-68.

23. Ng E, Pottie K, Spitzer D. Official language proficiency and self-reported health among immigrants to Canada. Health Rep 2011;22:15-23.

24. Lasser KE, Himmelstein DU, Woolhandler S. Access to care, health status, and health disparities in the united states and Canada: results of a crossnational population-based survey. Am J Public Health 2006;96:1300-7.

25. Kirst M, Shankardass K, Bomze S, Lofters A, Quiñonez C. Sociodemographic data collection for health equity measurement: a mixed methods study examining public opinions. Int J Equity Health 2013; $12: 75$. 
26. Hasnain-Wynia R, Baker DW. Obtaining data on patient race, ethnicity, and primary language in health care organizations: current challenges and proposed solutions. Health Serv Res 2006;41(4 Pt 1):1501-18.

27. Iqbal G, Johnson MR, Szczepura A, Wilson S, Gumber A, Dunn JA. UK ethnicity data collection for healthcare statistics: the South Asian perspective. BMC Public Health 2012;12:243.

28. Hasnain-Wynia R, Taylor-Clark K, Anise A. Collecting race, ethnicity, and language data to identify and reduce health disparities: perceptions of health plan enrollees. Med Care Res Rev 2011;68: 367-81.

29. Wynia MK, Ivey SL, Hasnain-Wynia R. Collection of data on patients' race and ethnic group by physician practices. N Engl J Med 2010;362:846-50.

30. Hasnain-Wynia R, Van Dyke K, Youdelman M, et al. Barriers to collecting patient race, ethnicity, and primary language data in physician practices: an exploratory study. J Natl Med Assoc 2010;102: $769-75$.

31. Nerenz DR, Currier C, Paez K. Collection of data on race/ethnicity by private sector organizations: results of a medical group survey. In: Ver Ploeg M, Perrin E, eds. Eliminating disparities: measurement and data needs. Washington, DC: National Academies Press; 2004:249-71.

32. Lofters AK, Shankardass K, Kirst M, Quinonez C. Sociodemographic data collection in healthcare settings: an examination of public opinions. Med Care 2011;49:193-9.

33. Shankardass K, Lofters A, Kirst M, Quinonez C. Public awareness of income-related health inequalities in Ontario, Canada. Int J Equity Health 2012; 11:26.

34. Baker DW, Hasnain-Wynia R, Kandula NR, Thompson JA, Brown ER. Attitudes toward health care providers, collecting information about patients' race, ethnicity, and language. Med Care 2007;45: $1034-42$.

35. Murphy K, Glazier R, Wang X, Holton E, Fazli G, Ho M. Hospital care for all: an equity report on differences in household income among patients at Toronto Central Local Health Integration Network (TC LHIN) hospitals, 2008-2010. Toronto: Institute for Clinical Evaluative Sciences (ICES); 2012.
36. Bierman AS, Lurie N, Collins KS, Eisenberg JM. Addressing racial and ethnic barriers to effective health care: the need for better data. Health Aff (Millwood) 2002;21:91-102.

37. Dorsey R, Graham G. New HHS data standards for race, ethnicity, sex, primary language, and disability status. JAMA 2011;306:2378-9.

38. Subcommittee on Standardized Collection of Race/ Ethnicity Data for Healthcare Quality Improvement Board on Health Care Services, Ulmer C, McFadden B, Nerenz DR, eds. Race, ethnicity, and language data: standardization for health care quality improvement. Institute of Medicine report. Washington, DC: Agency for Healthcare Research and Quality; 2009. Available from: http://www.ahrq.gov/ research/findings/final-reports/iomracereport/index. html. Accessed March 31, 2016.

39. Weinick RM, Zuvekas SH, Cohen JW. Racial and ethnic differences in access to and use of health care services, 1977 to 1996. Med Care Res Rev 2000; 57(Suppl 1):36-54.

40. St. Michael's Hospital. The Tri-Hospital + Toronto Public Health Health Equity Data Collection Research Project report. Available from: http:// www.stmichaelshospital.com/quality/data-collectionresearch-project.php. Updated 2013. Accessed December 12, 2013.

41. Baker DW, Cameron KA, Feinglass J, et al. Patients' attitudes toward health care providers collecting information about their race and ethnicity. J Gen Intern Med 2005;20:895-900.

42. Palaniappan LP, Wong EC, Shin JJ, Moreno MR, Otero-Sabogal R. Collecting patient race/ethnicity and primary language data in ambulatory care settings: a case study in methodology. Health Serv Res 2009;44(5 Pt 1):1750-61.

43. Weissman JS, Hasnain-Wynia R. Advancing health care equity through improved data collection. N Engl J Med 2011;364:2276-7.

44. Baker DW, Cameron KA, Feinglass J, et al. A system for rapidly and accurately collecting patients' race and ethnicity. Am J Public Health 2006;96:532-7.

45. Jorgensen S, Thorlby R, Weinick RM, Ayanian JZ. Responses of Massachusetts hospitals to a state mandate to collect race, ethnicity and language data from patients: a qualitative study. BMC Health Serv Res 2010;10:352. 


\section{Appendix 1}

\section{Rationale for Questions Used in the Tri-Hospital + Toronto Public Health Equity Data Collection Research Project}

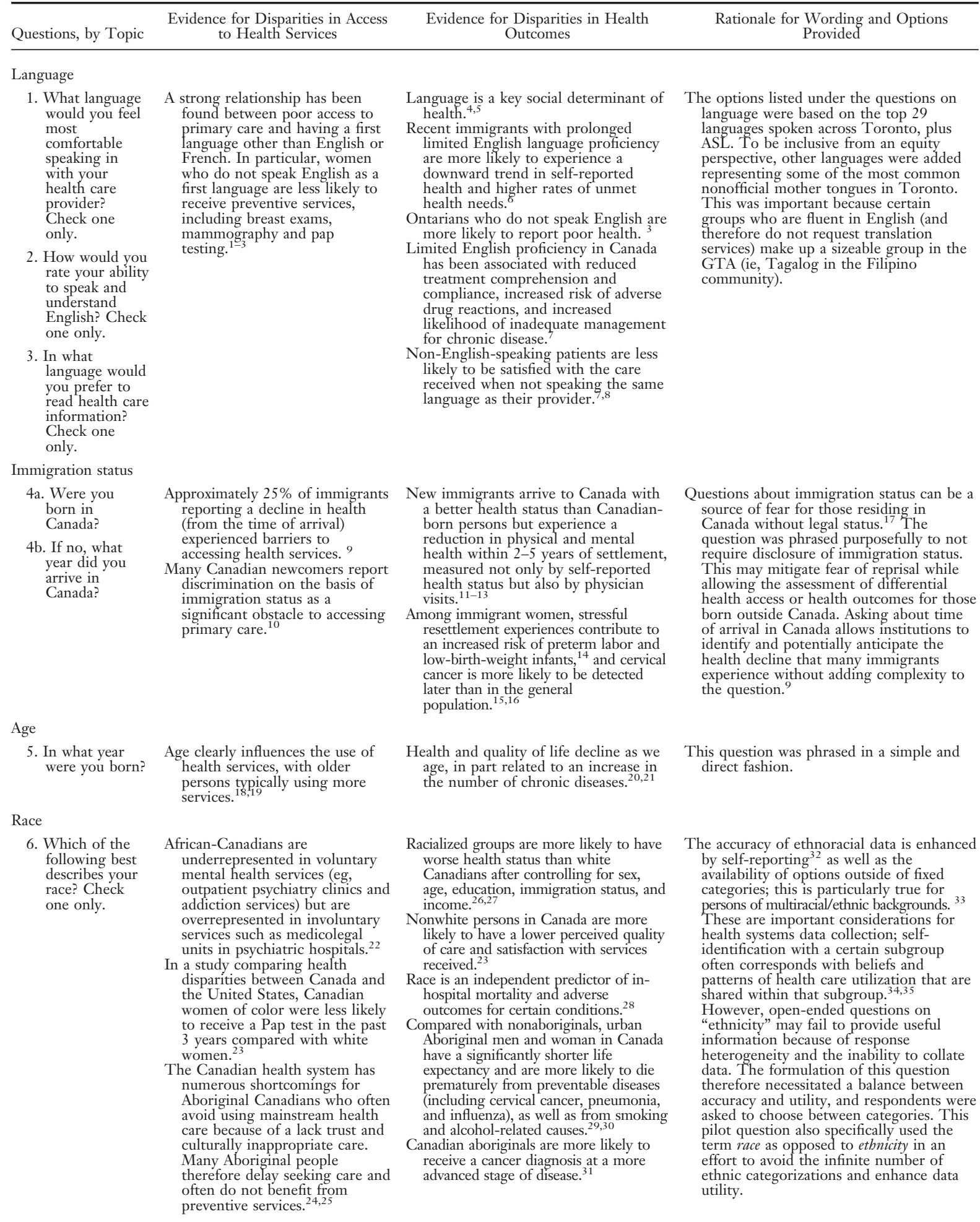

Continued 
Appendix 1 Continued

Rationale for Wording and Options Provided

\begin{tabular}{|c|c|c|}
\hline Questions, by Topic & $\begin{array}{l}\text { Evidence for Disparities in Access } \\
\text { to Health Services }\end{array}$ & $\begin{array}{l}\text { Evidence for Disparities in Health } \\
\text { Outcomes }\end{array}$ \\
\hline \multicolumn{3}{|l|}{ Religion } \\
\hline $\begin{array}{l}\text { 7. What is your } \\
\text { religious or } \\
\text { spiritual } \\
\text { affiliation? } \\
\text { Check one } \\
\text { only. }\end{array}$ & $\begin{array}{l}\text { Few Canadian studies have explored } \\
\text { faith-based disparities in access to } \\
\text { health care. One study from } \\
\text { Newfoundland found that } \\
\text { Muslim women identified } \\
\text { providers' lack of awareness and } \\
\text { insensitivity to religious } \\
\text { differences as a reason for unmet } \\
\text { maternal care needs. }{ }^{36}\end{array}$ & $\begin{array}{l}\text { The capacity of health care providers to } \\
\text { understand and accommodate a } \\
\text { patient's spiritual and religious } \\
\text { paradigms can affect routine } \\
\text { care }^{24,36,37} \text { and end-of-life care and is } \\
\text { increasingly important for patient } \\
\text { satisfaction within the health care } \\
\text { system. }{ }^{38-40}\end{array}$ \\
\hline \multicolumn{3}{|l|}{ Disability } \\
\hline $\begin{array}{l}\text { 8. Do you have } \\
\text { any of the } \\
\text { following } \\
\text { disabilities? } \\
\text { Check all that } \\
\text { apply. }\end{array}$ & $\begin{array}{l}\text { People with disabilities often } \\
\text { require greater health care } \\
\text { attention because of comorbid } \\
\text { conditions that occur with } \\
\text { higher frequencies or differ } \\
\text { from those faced by the general } \\
\text { population; however, there is a } \\
\text { trend of service underutilization } \\
\text { within this group that is } \\
\text { inversely correlated with } \\
\text { disability severity. } \\
\text { Factors making this population } \\
\text { particularly vulnerable to } \\
\text { disparities in access (and } \\
\text { outcomes) include functional } \\
\text { and communication limitations } \\
\text { as well as systemic barriers such } \\
\text { as inadequate facilities and } \\
\text { insufficient training for health } \\
\text { care professionals. }{ }^{+1,44}\end{array}$ & $\begin{array}{l}\text { There is considerable evidence that } \\
\text { certain intellectual disabilities are } \\
\text { associated with higher rates of } \\
\text { morbidity and shorter life } \\
\text { expectancies compared with people } \\
\text { without disabilities. }{ }^{44-46} \\
\text { The multiplicative effect of overlapping } \\
\text { social determinants is shown strongly } \\
\text { within this group. For example, } \\
\text { Aboriginal people with epilepsy are less } \\
\text { likely to see a neurologist but more } \\
\text { likely to visit the emergency } \\
\text { department or be hospitalized, whereas } \\
\text { lower socioeconomic status is } \\
\text { associated with poor medication } \\
\text { compliance. } \\
\text { Also, nonwhite people with Down } \\
\text { syndrome have a higher mortality rate } \\
\text { than white persons with Down } \\
\text { syndrome. } \\
\text { Psychotropic medications are prescribed } \\
\text { with a high frequency for people with } \\
\text { intellectual disabilities for behavioral or } \\
\text { emotional problems; however, incorrect } \\
\text { diagnoses often lead to misuse of these } \\
\text { drugs, with significant adverse effects for } \\
\text { cognition, mobility, and bone and } \\
\text { metabolic health. }\end{array}$ \\
\hline
\end{tabular}

Gender
9. What is your gender? Check one only.
Studies focusing on trans and intersex populations have identified stigma and discrimination as limiting access and quality of care. ${ }^{50}$

Approximately half $(52 \%)$ of trans people surveyed reported negative experiences in the emergency department on the basis of their gender, whereas $21 \%$ reported avoiding care in the emergency department because of fear of a negative encounter. $^{52}$
Research focusing on differences in care between the male and female sexes has uncovered inexplicable disparities across all levels of health care after controlling for potentially diseasemitigating factors. ${ }^{3,54,55}$ For instance, women with coronary syndromes are less likely to be admitted to acute care and receive revascularization procedures compared with men and more likely to die after a critical illness in hospital. ${ }^{56}$
Religion is a key social determinant of health. ${ }^{4,5}$ The major religious denominations of people living in Ontario were included in the survey. To be inclusive from an equity perspective, other major world religions were included, such as Wicca, Zoroastrianism, and Jainism, as well as less common spiritual affiliations.

All of the options provided under the question on disability were adopted from the OHRC definition of disability. ${ }^{49}$ OHRC definitions for each type of disability were linked to the question and could be referenced while completing the survey. Acknowledging that often multiple disabilities coexist, participants were prompted to select "all that apply."

There is a need to separate sex from gender in health research to understand and measure the impacts of gender relations, identity, and sex-linked biology. ${ }^{53}$

Whereas sex refers to one's biological status, assigned at birth, gender is tied to a person's sense of self. Thus gender identity can be male, female, both, or neither; it differs from sex and is distinct from sexual orientation. Within the survey, "trans" was used an abbreviation and umbrella term to include transgender, transsexual, gender nonconforming, and gender questioning. "Intersexuality" was meant to include those with physical and/ or chromosomal variations where features often considered either male or female are combined into one body. ${ }^{57}$

Gender has been identified by the PHAC as a key social determinant of health. ${ }^{58}$

Lesbian, gay and bisexual persons

10. What is your sexual orientation? Check one only. formulated based on consensus among the steering committee, which consisted of multiple health equity experts and researchers.
LGB Canadians consistently report more negative experiences within the health system 59,60

When encounters are not overtly discriminatory, LGB patients are treated "just like everybody else," with inattention to the unique health needs of this population. ${ }^{61,62}$

Many LGB persons do not divulge sexual orientation for fear of provider bias, ${ }^{63}$ and experiences of stigma leads to future avoidance or delay of care seeking. ${ }^{59,64}$

Lesbians are less likely to see a family physician for a Pap test than heterosexual women. ${ }^{64}$
Canadian LGB youth are at higher risk of suffering from mental illness (including suicidal ideation, suicide attempts, and depression), physical and sexual abuse, homelessness, and exposure to human immunodeficiency virus. ${ }^{65}$

Once again, the options provided for this question were designed as a balance between inclusivity (creating categories that people can identify with) and the need for utility in measurement and analysis.

Continued 


\section{Appendix 1 Continued}

\begin{tabular}{|c|c|c|c|}
\hline Questions, by Topic & $\begin{array}{l}\text { Evidence for Disparities in Access } \\
\text { to Health Services }\end{array}$ & $\begin{array}{l}\text { Evidence for Disparities in Health } \\
\text { Outcomes }\end{array}$ & $\begin{array}{c}\text { Rationale for Wording and Options } \\
\text { Provided }\end{array}$ \\
\hline \multicolumn{4}{|l|}{ Income } \\
\hline $\begin{array}{l}\text { 11. What was } \\
\text { your total } \\
\text { family income } \\
\text { before taxes last } \\
\text { year? Check } \\
\text { one only. } \\
\text { 12. How many } \\
\text { people does } \\
\text { this income } \\
\text { support? }\end{array}$ & $\begin{array}{l}\text { Low-income persons have lower } \\
\text { access to specialist }{ }^{66-70} \text { and } \\
\text { primary care compared with } \\
\text { high-income persons. }\end{array}$ & $\begin{array}{l}\text { Poverty in Canada is strongly correlated } \\
\text { with the chronicity and severity of } \\
\text { disease, with poorer treatment } \\
\text { outcomes. } \\
\text { Canadians with a very low income } \\
\text { experience as much as } 9.8 \text { years' } \\
\text { difference in their life expectancy } \\
\text { compared with the wealthy. }{ }^{33} \\
\text { Low-income Canadians are }>2 \text { times as } \\
\text { likely to die of conditions for which } \\
\text { effective preventive measures and/or } \\
\text { treatment options exist, including } \\
\text { diabetes, cervical cancer, and }_{\text {suicide. }}{ }^{34}\end{array}$ & $\begin{array}{l}\text { Income has been identified by the PHAC as } \\
\text { a key social determinant of health } \\
\text { ("income and social status"). }{ }^{75} \text { Income } \\
\text { brackets were developed in } \$ 10,000 \\
\text { increments so that they would be narrow } \\
\text { enough to capture the LICOs but broad } \\
\text { enough that participants would feel } \\
\text { comfortable selecting a category. Asking } \\
\text { about the number of dependents } \\
\text { supported by the income allows for a } \\
\text { more accurate assessment of poverty and } \\
\text { its effect on health as LICO vary by } \\
\text { family size (ie, LICO in } 2009 \text { was } \$ 18,421 \\
\text { for an individual but } \$ 34,829 \text { for a family } \\
\text { of } 4) .76\end{array}$ \\
\hline \multicolumn{4}{|l|}{ Housing status } \\
\hline $\begin{array}{l}\text { 13. What type of } \\
\text { housing do you } \\
\text { live in? Check } \\
\text { one only. }\end{array}$ & $\begin{array}{l}\text { People who are homeless often } \\
\text { feel unwelcomed within the } \\
\text { health system and cite } \\
\text { discriminatory treatment as a } \\
\text { reason for avoidance. }\end{array}$ & $\begin{array}{l}\text { Canada's homeless suffer from higher } \\
\text { levels of disease are more likely to } \\
\text { die prematurely. } 78,79 \\
\text { Persons without a fixed address are } \\
\text { more likely report poor health status } \\
\text { and experience difficulty securing } \\
\text { appropriate care. }{ }^{80-82}\end{array}$ & $\begin{array}{l}\text { Categories selected for this question were } \\
\text { formulated based on consensus among the } \\
\text { steering committee, based on an } \\
\text { understanding of options available in } \\
\text { Toronto. Steering committee members } \\
\text { had extensive experience working with } \\
\text { patients who were homeless or } \\
\text { underhoused. }\end{array}$ \\
\hline
\end{tabular}

ASL, American Sign Language; GTA, Greater Toronto Area; LGB, lesbian, gay, and bisexual; LICO, low-income cutoff; OHRC, Ontario Human Rights Commission; PHAC, Public Health Agency of Canada.

1. Woloshin S, Schwartz LM, Katz SJ, Welch HG. Is language a barrier to the use of preventive services? J Gen Intern Med 1997;12:472-7.

2. Choudhry UK, Srivastava R, Fitch MI. Breast cancer detection practices of South Asian women: knowledge, attitudes, and beliefs. Oncol Nurs Forum 1998;25:1693-701.

3. Bierman AS, Johns A, Hyndman B, Mitchell C, Degani N, Shack AR, Creatore MI, Lofters AK, Urquia ML, Ahmad F, Khanlou N, Parlette V, eds. Chapter 12: Social determinants of health and populations at risk. In: Bierman AS, ed. Project for an Ontario Women's health Evidence-based Report: Volume 2. Toronto; 2012.

4. Raphael D. Social determinants of health: Canadian perspectives. 2nd ed. Toronto: Canadian Scholars' Press; 2008.

5. Commission on the Social Determinants of Health. Closing the gap in a generation: health equity through action on the social determinants of health. Final Report of the Commission on Social Determinants of Health. Geneva: World Health Organisation; 2008. 6. Wu Z, Penning MJ, Schimmele CM. Immigrant status and unmet health care needs. Can J Public Health 2005;96:369-73.

7. Bowen S. Language barriers in access to health care. Ottawa: Health Canada; 2001.

8. Dastjerdi M, Olson K, Ogilvie L. A study of Iranian immigrants' experiences of accessing Canadian health care services: a grounded theory. Int J Equity Health 2012;11:55.

9. Fuller-Thomson E, Noack AM, George U. Health decline among recent immigrants to Canada: findings from a nationallyrepresentative longitudinal survey. Can J Public Health 2011;102:273-80.

10. Pollock G, Newbold B, Lafreniere G, Edge S. Perceptions of discrimination in health services experienced by immigrant minorities in Ontario. 2012.

11. Wang L, Hu W. Immigrant health, place effect and regional disparities in Canada. Soc Sci Med 2013;98:8-17.

12. Beiser M, Goodwill AM, Albanese P, McShane K, Nowakowski M. Predictors of immigrant children's mental health in Canada: selection, settlement contingencies, culture, or all of the above? Soc Psychiatry Psychiatr Epidemiol 2014;49:743-56.

13. Pottie K, Batista R, Mayhew M, Mota L, Grant K. Improving delivery of primary care for vulnerable migrants: Delphi consensus to prioritize innovative practice strategies. Can Fam Physician 2014;60:e32-40.

14. Patrick TE, Bryan Y. Research strategies for optimizing pregnancy outcomes in minority populations. Am J Obstet Gynecol 2005;192(5 Suppl):S64-70.

15. National Cancer Institute of Canada. Cancer statistics 2005. Available from: http://www.cancer.ca/ /media/cancer.ca/CW/ cancer\%20information/cancer\%20101/Canadian\%20cancer\%20statistics/Canadian-Cancer-Statistics-2005-EN.pdf. Updated 2005. Accessed September 3, 2014.

16. Oelke ND, Vollman AR. "Inside and outside": Sikh women's perspectives on cervical cancer screening. Can J Nurs Res 2007;39:174-89.

17. Magalhaes L, Carrasco C, Gastaldo D. Undocumented migrants in Canada: a scope literature review on health, access to services, and working conditions. J Immigr Minor Health 2010;12:132-51.

18. Stukel TA, Fisher ES, Alter DA, et al. Association of hospital spending intensity with mortality and readmission rates in Ontario hospitals. JAMA 2012;307:1037-45.

19. Austin PC, van Walraven C, Wodchis WP, Newman A, Anderson GM. Using the Johns Hopkins aggregated diagnosis groups (ADGs) to predict mortality in a general adult population cohort in Ontario, Canada. Med Care 2011;49:932-9.

20. Hogan DB, Amuah JE, Strain LA, et al. High rates of hospital admission among older residents in assisted living facilities: opportunities for intervention and impact on acute care. Open Med 2014;8:e33-45.

21. Sibley LM, Glazier RH. Evaluation of the equity of age-sex adjusted primary care capitation payments in Ontario, Canada. Health Policy 2012;104:186-92. 


\section{Appendix 1 Continued}

\begin{tabular}{lccc}
\hline Questions, by Topic & $\begin{array}{c}\text { Evidence for Disparities in Access } \\
\text { to Health Services }\end{array}$ & $\begin{array}{c}\text { Evidence for Disparities in Health } \\
\text { Outcomes }\end{array}$ & $\begin{array}{c}\text { Rationale for Wording and Options } \\
\text { Provided }\end{array}$ \\
\hline
\end{tabular}

22. Annoual PC, Bibeau G, Marshall C, Sterlin C. Developing a new service model for Canadians of African descent: enslavement, colonization, racism, identity and mental health. Toronto: Centres for Addiction and Mental Health; 2007. Available from: http://www.camhx.ca/Publications/Resources_for_Professionals/EACRIMH/eacrimh_report1107.pdf. Accessed March 19, 2015.

23. Lasser KE, Himmelstein DU, Woolhandler S. Access to care, health status, and health disparities in the united states and Canada: results of a cross-national population-based survey. Am J Public Health 2006;96:1300-7.

24. Access to health services as a social determinant of First Nations, Inuit and Métis health. Prince George, British Columbia, CA: National Collaborating Centre for Aboriginal Health; 2011.

25. Empathy, dignity, and respect: creating cultural safety for aboriginal people in urban health care. Toronto: Health Council of Canada; 2012.

26. Veenstra G. Racialized identity and health in Canada: results from a nationally representative survey. Soc Sci Med 2009;69:53842.

27. Hyman I. Racism as a determinant of immigrant health. Policy brief to Public Health Agency of Canada. March $20,2009$. Available from: http://canada.metropolis.net/pdfs/racism_policy_brief_e.pdf. Accessed March 19, 2015.

28. McNabb-Baltar J, Trinh QD, Barkun AN. Disparities in outcomes following admission for cholangitis. PLoS One 2013;8:e59487.

29. Tjepkema M, Wilkins R, Senécal S, Guimond E, Penney C. Mortality of Métis and registered Indian adults in Canada: an 11-year follow-up study. Health Rep 2009;20:31-51.

30. Tjepkema M, Wilkins R, Senécal S, Guimond E, Penney C. Mortality of urban aboriginal adults in Canada, 1991-2001. Chronic Dis Can 2010;31:4-21.

31. Morrisseau K. Aboriginal cancer control progress report. Available from: http://www.cancercare.mb.ca/resource/File/ Aboriginal_CancerControlProgressReport_07-08.pdf. Accessed September 3, 2014.

32. Hasnain-Wynia R, Pierce D, Haque A, Hedges Greising C, Prince V, Reiter J. Health research and educational trust disparities toolkit. Available from: http://www.hretdisparities.org/. Accessed September 3, 2014.

33. Hasnain-Wynia R, Baker DW. Obtaining data on patient race, ethnicity, and primary language in health care organizations: current challenges and proposed solutions. Health Serv Res 2006;41(4 Pt 1):1501-18.

34. Hasnain-Wynia R, Van Dyke K, Youdelman M, et al. Barriers to collecting patient race, ethnicity, and primary language data in physician practices: an exploratory study. J Natl Med Assoc 2010;102:769-75.

35. Wynia MK, Ivey SL, Hasnain-Wynia R. Collection of data on patients' race and ethnic group by physician practices. N Engl J Med 2010;362:846-50.

36. Reitmanova S, Gustafson DL. "They can't understand it": maternity health and care needs of immigrant Muslim women in St. John's, Newfoundland. Matern Child Health J 2008;12:101-11.

37. Lee R, Rodin G, Devins G, Weiss MG. Illness experience, meaning and help-seeking among Chinese immigrants in Canada with chronic fatigue and weakness. Anthropol Med 2001;8:89-107.

38. Balboni TA, Vanderwerker LC, Block SD, et al. Religiousness and spiritual support among advanced cancer patients and associations with end-of-life treatment preferences and quality of life. J Clin Oncol 2007;25:555-60.

39. Ehman JW, Ott BB, Short TH, Ciampa RC, Hansen-Flaschen J. Do patients want physicians to inquire about their spiritual or religious beliefs if they become gravely ill? Arch Intern Med 1999;159:1803-6.

40. Koenig H. Spirituality in patient care. Philadelphia: Templeton Foundation Press; 2007.

41. Alborz A, McNally R, Glendinning C. Access to health care for people with learning disabilities in the UK: mapping the issues and reviewing the evidence. J Health Serv Res Policy 2005;10:173-82.

42. Sullivan WF, Berg JM, Bradley E, et al. Primary care of adults with developmental disabilities: Canadian consensus guidelines. Can Fam Physician 2011;57:541-53, e154-68.

43. Wei W, Findley PA, Sambamoorthi U. Disability and receipt of clinical preventive services among women. Womens Health Issues 2006;16:286-96.

44. Ouellette-Kuntz H, Garcin N, Lewis ME, Minnes P, Martin C, Holden JJ. Addressing health disparities through promoting equity for individuals with intellectual disability. Can J Public Health 2005;96(Suppl 2):S8-22.

45. Bittles AH, Petterson BA, Sullivan SG, Hussain R, Glasson EJ, Montgomery PD. The influence of intellectual disability on life expectancy. J Gerontol A Biol Sci Med Sci 2002;57:M470-2.

46. Balogh R, Ouellette-Kuntz H, Hunter D. Regional variation in dental procedures among people with an intellectual disability, Ontario, 1995-2001. J Can Dent Assoc 2008;70:681-8.

47. Burneo JG, Jette N, Theodore W, et al. Disparities in epilepsy: report of a systematic review by the North American Commission of the International League Against Epilepsy. Epilepsia 2009;50:2285-95.

48. Yang Q, Rasmussen SA, Friedman JM. Mortality associated with Down's syndrome in the USA from 1983 to 1997 : a population-based study. Lancet 2002;359:1019-25.

49. Disability and human rights (brochure). Toronto: Ontario Human Rights Commission; 2014. Available from: http:// www.ohrc.on.ca/en/disability-and-human-rights-brochure. Accessed September 4, 2014.

50. Lesbian health: current assessment and directions for the future. Washington, DC: Institute of Medicine; 1999.

51. Kaufman R. Introduction to transgender identity and health. In: Mukadon H, Mayer K, Potter J, Goldhammer H, eds. The Fenway guide to lesbian, gay, bisexual, and transgender health. Philadelphia: American College of Physicians; 2007.

52. Bauer GR, Scheim AI, Deutsch MB, Massarella C. Reported emergency department avoidance, use, and experiences of transgender persons in Ontario, Canada: results from a respondent-driven sampling survey. Ann Emerg Med 2014;63:713-20.e1.

Continued 


\section{Appendix 1 Continued}

\begin{tabular}{lccc}
\hline Questions, by Topic & $\begin{array}{c}\text { Evidence for Disparities in Access } \\
\text { to Health Services }\end{array}$ & $\begin{array}{c}\text { Evidence for Disparities in Health } \\
\text { Outcomes }\end{array}$ & Rationale for Wording and Options \\
Provided & &
\end{tabular}

53. Scheim AI, Bauer GR. Sex and gender diversity among transgender persons in Ontario, Canada: results from a respondent-driven sampling survey. J Sex Res 2015;52:1-14.

54. Fowler RA, Sabur N, Li P, et al. Sex-and age-based differences in the delivery and outcomes of critical care. CMAJ 2007;177: $1513-9$.

55. Birnie DH, Sambell C, Johansen H, et al. Use of implantable cardioverter defibrillators in Canadian and US survivors of out-of-hospital cardiac arrest. CMAJ 2007;177:41-6.

56. Kaul P, Chang WC, Westerhout CM, Graham MM, Armstrong PW. Differences in admission rates and outcomes between men and women presenting to emergency departments with coronary syndromes. CMAJ 2007;177:1193-9.

57. Holmes M. Intersex: a perilous difference. Selinsgrove, PA: Susquehanna University Press; 2008.

58. Public Health Agency of Canada. Population health approach - what determines health? Web site. Available from: http:// www.phac-aspc.gc.ca/ph-sp/determinants/index-eng.php. Updated 2001. Accessed March 4, 2009.

59. Bergeron S, Senn CY. Health care utilization in a sample of Canadian lesbian women: predictors of risk and resilience. Women Health 2003;37:19-35.

60. Tjepkema M. Health care use among gay, lesbian and bisexual Canadians. Health Rep 2008;19:53-64.

61. Brotman S, Ryan B, Jalbert Y, Rowe B. The impact of coming out on health and health care access: rhe experiences of gay, lesbian, bisexual and two-spirit people. J Health Soc Policy 2002;15:1-29.

62. Mayer KH, Bradford JB, Makadon HJ, Stall R, Goldhammer H, Landers S. Sexual and gender minority health: what we know and what needs to be done. Am J Public Health 2008;98:989-95.

63. Eliason M, Schope R. Does “don't ask don't tell” apply to health care? Lesbian, gay, and bisexual people's disclosure to health care providers. J Gay Lesbian Med Assoc 2001;5:125-34.

64. Tjepkema M. Health care use among gay, lesbian and bisexual Canadians. Health Rep 2008;19:53-64.

65. Ylioja T, Craig SL. Exclusionary health policy: responding to the risk of poor health among sexual minority youth in Canada. Soc Work Public Health 2014;29:81-6.

66. van Doorslaer E, Masseria C, Koolman X; OECD Health Equity Research Group. Inequalities in access to medical care by income in developed countries. CMAJ 2006;174:177-83.

67. Alter D, Naylor C, Austin P, Tu J. Effects of socieoeconomic status on acccess to invasive cardiac procedures and on mortality after acute myocardial infarction. N Engl J Med 1999;341:1359-67.

68. Alter D, Naylor C, Austin P, Chan B, Tu J. Geography and service supply do not explain socioeconomic gradients in angiography use after acute myocardial infarction. CMAJ 2003;168:261-4.

69. Dunlop S, Coyte PC, McIsaac W. Socio-economic status and the utilisation of physicians' services: results from the Canadian National Population Health Survey. Soc Sci Med 2000;51:123-33.

70. Roos NP, Mustard CA. Variation in health and health care use by socioeconomic status in Winnipeg, Canada: does the system work well? yes and no. Milbank Q 1997;75:89-111.

71. Olah ME, Gaisano G, Hwang SW. The effect of socioeconomic status on access to primary care: an audit study. CMAJ 2013;185:E263-9.

72. Auger N, Raynault M, Lessard R, Choiniere R. Income and health in Canada. In: Raphael D, ed. Social determinants of health: Canadian perspectives. Toronto: Canadian Scholars Press; 2004:39-52.

73. Stratton J, Mowat DL, Wilkins R, Tjepkema M. Income disparities in life expectancy in the City of Toronto and region of Peel, Ontario. Chronic Dis Inj Can 2012;32:208-15.

74. Tjepkema M, Wilkins R, Long A. Socio-economic inequalities in cause-specific mortality: a 16-year follow-up study. Can J Public Health 2013;104:e472-8

75. Public Health Agency of Canada. Population health approach-what is the population health approach? Updated January 15, 2013. Available from: http://www.phac-aspc.gc.ca/ph-sp/approach-approche/appr-eng.php. Accessed March 31, 2016.

76. Statistics Canada. Low Income Lines, 2009-2010. Ottawa, 2011. Available from: http://www.statcan.gc.ca/pub/75f0002m/ 75f0002m2011002-eng.pdf. Accessed April 15, 2016.

77. Wen CK, Hudak PL, Hwang SW. Homeless people's perceptions of welcomeness and unwelcomeness in healthcare encounters. J Gen Intern Med 2007;22:1011-7.

78. Cheung AM, Hwang SW. Risk of death among homeless women: a cohort study and review of the literature. CMAJ 2004;170:1243-7.

79. Frankish CJ, Hwang SW, Quantz D. Homelessness and health in Canada: research lessons and priorities. Can J Public Health 2005;96(Suppl 2):S23-9.

80. Hwang S. Homelessness and health. CMAJ 2005;164:229-33.

81. Levitt AJ, Culhane DP, DeGenova J, O'Quinn P, Bainbridge J. Health and social characteristics of homeless adults in Manhattan who were chronically or not chronically unsheltered. Psychiatr Serv 2009;60:978-81.

82. Zakrison T, Hamel P, Hwang S. Homeless people's trust and interactions with police and paramedics. J Urban Health 2004;81:596-605. 


\section{Appendix 2}

Survey Questions on Sociodemographic Variables

Used in a Pilot Study in the Department of Family

and Community Medicine, St. Michael's Hospital,

During Summer 2012

1. What language would you feel most comfortable speaking in with your health care provider? Check one only.

American Sign Language

Arabic

Bengali

Chinese (Cantonese)

Chinese (Mandarin)

Cree

Dari

English

Farsi (Persian)

French

German

Greek

Gujarati

Hebrew

Hindi

Hungarian

Italian

Korean

Oji-Cree

Ojibwe

Polish

Portuguese

Punjabi

Russian

Somali

Spanish

Tagalog

Tamil

Urdu

Vietnamese

Other (Please specify)

Do not know

Prefer not to answer

2. How would you rate your ability to speak and understand English? Check one only.

Very well

Well

Not well

Not at all

Unsure

Prefer not to answer

Do not know
3. In what language would you prefer to read health care information? Check one only.

Arabic

Bengali

Braille

Chinese (Modern)

Chinese (Traditional)

Cree

Dari

English

Farsi (Persian)

French

German

Greek

Gujarati

Hebrew

Hindi

Hungarian

Italian

Korean

Oji-Cree

Ojibwe

Polish

Portuguese

Punjabi

Russian

Somali

Spanish

Tagalog

Tamil

Urdu

Vietnamese

Other (Please specify)

Prefer not to answer

Do not know

4. Were you born in Canada?

Yes

No

Prefer not to answer

Do not know

If no, what year did you arrive in Canada?

5. In what year were you born?

Prefer not to answer

Do not know

6. Which of the following best describes your race? Check one only.

Aboriginal (eg, Inuit, First Nations, Non-status Indian, Métis, Aboriginal person from outside Canada) 
Asian-East (eg, Chinese, Japanese, Korean)

Asian-South (eg, Indian, Pakistani, Sri Lankan, Indo-Caribbean)

Asian-South East (eg, Malaysian, Filipino, Vietnamese)

Black-Africa (eg, Ghanaian, Kenyan, Somali)

Black-Caribbean region (eg, Barbadian, Jamaican)

Black-North America

Latin American (eg, Argentinean, Chilean, Salvadoran)

Middle Eastern (eg, Egyptian, Iranian, Lebanese)

Mixed heritage (Please specify)

White/European (eg, English, Italian, Portuguese, Russian)

Other(s) (Please specify)

Prefer not to answer

Do not know

7. What is your religious or spiritual affiliation?

Check one only.

I do not have a religious or spiritual affiliation.

Animism or Shamanism

Atheism

Baha'i faith

Buddhism

Christian Orthodox

Christian, not included elsewhere on this list

Christianity

Confucianism

Hinduism

Islam

Jainism

Judaism

Native spirituality

Protestant

Rastafarianism

Roman Catholic

Sikhism

Spiritual

Unitarianism

Wicca

Zoroastrianism

Other (Please specify)

Prefer not to answer

Do not know

8. Do you have any of the following disabilities?

Check all that apply.

No disabilities

Physical disability

Chronic illness
Sensory disability (ie, hearing or vision loss)

Developmental disability

Drug or alcohol dependence

Learning disability

Mental illness

Other (Please specify)

Prefer not to answer

Do not know

9. What is your gender? Check one only.

Female

Male

Trans

Intersex

Prefer not to answer

Do not know

10. What is your sexual orientation? Check one only.

Heterosexual ("straight”)

Gay

Lesbian

Bisexual

Two-spirit

Queer

Questioning

Prefer not to answer

Do not know

11. What was your total family income before taxes last year? Check one only.

$<\$ 10,000$

$\$ 10,000$ to $\$ 19,999$

$\$ 20,000$ to $\$ 29,999$

$\$ 30,000$ to $\$ 39,999$

$\$ 40,000$ to $\$ 49,999$

$\$ 50,000$ to $\$ 59,999$

$\$ 60,000$ to $\$ 79,999$

$\$ 80,000$ to $\$ 99,999$

$\$ 100,000$ to $\$ 150,000 \geq \$ 150,000$

Prefer not to answer

Do not know

12. How many people does this income support?

Prefer not to answer

Do not know

13. What type of housing do you live in? Check one only.

Rent

Own

Living with family or friends

Temporary housing (eg, shelter, hostel) or homeless

Correctional facility 
Other (specify):

Prefer not to answer

Do not know

14. In general, would you say your health is: (Check one only.)

Excellent

Very good

Good

Fair

Poor

Prefer not to answer

Do not know

\section{Appendix 3}

Survey Questions on Sociodemographic Variables

Implemented within the Department of Family and Community Medicine, St. Michael's Hospital, as of December 2013

Preamble: Measuring Health Equity

Please tell us about yourself.

We want to ask you 11 brief questions as part of our ongoing work to improve access and quality of care for all patients and to identify health inequities. It should take approximately $2-5$ minutes to complete.

Your participation is VOLUNTARY and you can stop at any time.

You do not have to complete the survey if you don't want to. You can skip questions.

The information you share with us will be safely kept with your medical file.

This will not affect your access to care.

1. What language would you feel most comfortable speaking in with your healthcare provider? Check one only.

English

Amharic

Arabic

ASL

Bengali

Chinese (Cantonese)

Chinese (Mandarin)

Cree

Czech

Dari

Farsi

French

Greek

Hebrew

Hindi
Hungarian

Inuktitut

Italian

Karen

Korean

Nepali

Ojibwe

Oji-Cree

Polish

Portuguese

Punjabi

Russian

Serbian

Slovak

Somali

Spanish

Tagalog

Tamil

Tigrinya

Turkish

Twi

Ukrainian

Urdu

Vietnamese

Other (Please specify)

Prefer not to answer

Do not know

2. Were you born in Canada?

Yes

No

Prefer not to answer

Do not know

If no, what year did you arrive in Canada?

3. Which of the following best describes your racial or ethnic group? Check one only.

Asian-East (eg, Chinese, Japanese, Korean)

Asian-South (eg, Indian, Pakistani, Sri Lankan)

Asian-South East (eg, Malaysian, Filipino, Vietnamese)

Black-African (eg, Ghanaian, Kenyan, Somali)

Black-Caribbean (eg, Barbadian, Jamaican)

Black-North American (eg, Canadian, American)

First Nations

Indian -Caribbean (eg, Guyanese with origins in India)

Indigenous/aboriginal not included elsewhere

Inuit

Latin American (eg, Argentinean, Chilean, Salvadorian) 
Métis

Middle Eastern (eg, Egyptian, Iranian, Lebanese)

White-European (eg, English, Italian, Portuguese, Russian)

White-North American (eg, American, Canadian)

Mixed heritage (eg, black-African and whiteNorth American)

Other(s) (Please specify)

Prefer not to answer

Do not know

4. Do you have any of the following disabilities?

Check all that apply.

None

Chronic illness

Developmental disability

Learning disability

Mental illness

Physical disability

Sensory disability (ie, hearing or vision loss)

Drug or alcohol dependence

Other (Please specify)

Prefer not to answer

Do not know

5. What is your sex/gender? Check one only.

Female

Male

Trans-Female to Male

Trans-Male to Female

Intersex

Other (Please specify)

Prefer not to answer

Do not know

6. What is your sexual orientation? Check one only.

Heterosexual ("straight," male-female relationships)

Gay

Lesbian

Bisexual

Two-spirit

Queer

Other (Please specify)

Prefer not to answer

Do not know

7. What was your total family income before taxes last year? Check one only.

$\$ 0$ to $\$ 29,999$

$\$ 30,000$ to $\$ 59,999$

$\$ 60,000$ to $\$ 89,999$
$\$ 90,000$ to $\$ 119,999$

$\$ 120,000$ to $\$ 149,999$

$\geq \$ 150,000$

Prefer not to answer

Do not know

8. How many people does this income support?

Prefer not to answer

Do not know

9. In what language would you prefer to read healthcare information? Check one only.

English

Amharic

Arabic

Bengali

Braille

Chinese (Simplified)

Chinese (Traditional)

Cree

Czech

Dari

Farsi

French

Greek

Hebrew

Hindi

Hungarian

Inuktitut

Italian

Karen

Korean

Nepali

Ojibwe

Oji-Cree

Polish

Portuguese

Punjabi

Russian

Serbian

Slovak

Somali

Spanish

Serbian

Tagalog

Tamil

Tigrinya

Turkish

Twi

Ukrainian

Urdu

Vietnamese 
Other (Please specify)

Prefer not to answer

Do not know

10 . What is your religious or spiritual affiliation? Check one only.

I do not have a religious or spiritual affiliation.

Christian Orthodox

Protestant

Roman Catholic

Christian, not included elsewhere on this list

Animism or Shamanism

Atheism

Baha'i faith

Buddhism

Confucianism

Hinduism

Islam

Jainism

Jehovah's Witness

Judaism

Native spirituality

Pagan
Rastafarianism

Sikhism

Spiritualism

Unitarianism

Zoroastrianism

Other (Please specify)

Prefer not to answer

Do not know

11. What type of housing do you live in? Check one only.

Own home

Renting home

Boarding home

Correctional facility

Homeless/on street

Group home

Shelter/hostel

Supportive housing

Other (Please specify)

Prefer not to answer

Do not know

Thank you for participating in this survey. 